\title{
Changes in the Geomagnetic Field Associated with Earthquakes in the Izu Peninsula, Japan
}

\author{
T. Rikitake, ${ }^{*}$ Y. Honkura, ${ }^{*}$ H. Tanaka, ${ }^{*}$ N. Ohshiman, ${ }^{*}$ Y. Sasai, ${ }^{* *}$ \\ Y. IshiKawa, ** S. Koyama, ${ }^{* *}$ M. KaWamura,*** \\ and $\mathrm{K} . \mathrm{OHCHI} * * *$ \\ * Department of Applied Physics, Tokyo Institute of Technology, Tokyo, Japan \\ **Earthquake Research Institute, University of Tokyo, Tokyo, Japan \\ ***Kakioka Magnetic Observatory, Kakioka, Ibaraki-ken, Japan
}

(Received June 6, 1980)

Intensive observations of the geomagnetic field have been carried out since 1976 in the Izu Peninsula, Japan. An array of observation sites covers the area of anomalously high microearthquake activity persisting since 1975 . The array also extends over the region of crustal uplift amounting to $15 \mathrm{~cm}$ or thereabouts which was revealed at the beginning of 1976 . At present an observation system consisting of four types of stations is in operation. The total intensity of the geomagnetic field has been measured continuously by proton precession magnetometers at four stations. At two other temporary stations the total intensity is to be measured whenever earthquake activity becomes high in their vicinity. Three components of geomagnetic field variations have also been measured by a flux-gate magnetometer at another station. Finally, 45 observation sites have been established for repeated surveys of the total intensity. In addition to the repeated surveys at these sites, a smallscale experiment based on a synchronized measurement of difference in the total intensity between station pairs has been under way at an array of 14 sites located near the center of the crustal uplift.

During the period from 1976 to 1978, four major earthquakes took place within a distance of $30 \mathrm{~km}$ from the array: a $M 5.4$ event of August 1976, a $M 7.0$ one of January 1978, a $M 5.0$ one of November 1978, and a $M 5.4$ one of December 1978. In association with these earthquakes, some changes were detected in the total intensity and also in short-period geomagnetic variations. In the case of the largest event of magnitude 7.0, the difference in the total intensity between the two stations, where continuous measurements had been made, underwent a change about two months prior to the shock. The change was very similar in time sequence to that in the electric self-potential observed near one of the above two stations. Amplitudes of short-period geomagnetic variations also changed about two months before the shock. The result of repeated surveys disclosed a striking pattern of spatial distribution of presumably coseismic changes which is quite opposite to that obtained during a post-earthquake period. About two months prior to the $M 5.0$ earthquake 
which occurred several kilometers east of another station for continuous measurements, the total intensity remarkably decreased by $5 \mathrm{nT}$ or so at the station. The field abruptly recovered after its occurrence; a coseismic change amounted to about $5 \mathrm{nT}$. In the case of the $M 5.4$ event of 1978, no coseismic change was detected at a temporary station located a few kilometers west of the aftershock area. Changes in amplitude of short-period geomagnetic variations also appeared before this $M 5.4$ earthquake.

\section{Introduction}

In 1975, about one year after the Izu-Hanto Oki earthquake of magnitude 6.9, anomalously high microearthquake activity was found to have been taking place in the eastern part of Izu Peninsula (e.g. Tsumura et al., 1977). In the meantime, the levelling survey carried out in the beginning of 1976 disclosed an unusual crustal uplift amounting to $15 \mathrm{~cm}$ or thereabouts in the center of the anomalous area (GEOGRAPHICAL SURVEY INSTITUTE, 1976). Tectonic activity has become extremely high since then, so that various kinds of observations have been undertaken by many agencies in the Izu Peninsula (e.g. Earthquake Prediction Observation Center, 1977).

A number of remarkable earthquakes have taken place in and around the anomalous area, whereas the microearthquake activity and the crustal uplift still persist. Among them four earthquakes were greater than magnitude 5: a M5.4 earthquake of August 1976, a M7.0 one of January 1978, a M5.0 one of November 1978, and a M5.4 one of December 1978. The largest one of $M 7.0$ caused severe damages including loss of 25 lives. The main shock of this earthquake is associated with the displacement of a fault of about $17 \mathrm{~km}$ in length and $10 \mathrm{~km}$ in width with its slip amounting to about two meters (ShimAzAKI and Somerville, 1978). The epicenter of the main shock was located about $20 \mathrm{~km}$ east of the Izu Peninsula, while aftershocks extended to the western part of Izu Peninsula and the largest one of magnitude 5.8 occurred there (TSUMura et al., 1978).

As one of the field projects in the Izu Peninsula, observations of geomagnetic and telluric fields have been carried out intensively since 1976 by the following three research groups: the Earthquake Research Institute of the University of Tokyo, the Tokyo Institute of Technology, and the KakiokaMagnetic Observatory. The Earthquake Research Institute group has engaged in repeated surveys of the geomagnetic total intensity in the eastern half of Izu Peninsula along with continuous measurements of the total intensity at a few stations (SASAI and IsHIKAWA, 1977, 1978). It has also undertaken observations of short-period geomagnetic variations at a station (HoNKURA and KoYAma, 1978). The electric self-potential has also been measured there (Koyama and Honkura, 1978). The Tokyo Institute of Technology group has carried out repeated surveys of the total intensity in the western half of Izu Peninsula 
(TANAKA and OHSHIman, 1978; OHSHIMAn, 1980a) where a station for continuous measurements of the total intensity has been operated by the Kakioka Magnetic Observatory group (ОHCHI et al., 1979).

In view of the unusually high seismicity and the crustal uplift still persisting, more intensified observations have been required for the accumulation of otherwise inaccesible data relevant to earthquake occurrences and also for the contribution, if possible, to a practical prediction of earthquakes in the Izu Peninsula. Under such a situation, a geomagnetic group for researches in the Izu Peninsula was formed by the above three groups. This cooperative group is supposed to continue previous observations on individual basis yet under close communications and also to conduct cooperative observations whenever necessary.

The aim of this paper is to describe the observation system in the Izu Peninsula and some of the results obtained so far with much emphasis on changes associated with earthquake occurrences.

\section{Continuous Measurements of the Total Intensity}

In order to investigate changes in the geomagnetic field possibly associated with the crustal uplift, the Earthquake Research Institute (ERI) group set up a station at Sugehiki near the center of the anomalous uplift and continuous measurement of the total intensity was initiated in May, 1976. Meanwhile, another station for continuous measurement was established in November, 1976, near the western coast of Izu Peninsula by the Kakioka Magnetic Observatory (KMO) group. In view of high seismicity still going on and occurrences of some major earthquakes, the ERI group intensified the observation and established two more stations. Since September, 1978, four stations equipped with proton precession magnetometers, as indicated by $\mathrm{SH}, \mathrm{MZ}$, $\mathrm{KW}$, and UH in Fig. 1, have been in operation and the total intensity has been measured continuously. At present the operation of the station $\mathrm{UH}$ is halted and instead the total intensity is measured at a station newly established, as denoted by HS in Fig. 1.

The data obtained at the ERI stations are compared with the simultaneous ones obtained at a reference station; in the present case, the Kanozan Geodetic Observatory located about $100 \mathrm{~km}$ northeast of the $\mathrm{SH}$ station has been selected as the reference station. The KMO group compares the data at MZ with those at the Kakioka Magnetic Observatory as well as the above reference station. The differences in the total intensity between SH and other stations in the Izu Peninsula have also been monitored. Such differences will be useful if the difference in the total intensity between the Izu Peninsula area and the reference station is contaminated by effects of non-crustal origin such as spatial dependence of secular variations (e. g. SumIтomo, 1977).

The differences in the total intensity between respective stations $(\mathrm{SH}, \mathrm{KW}, \mathrm{UH})$ 


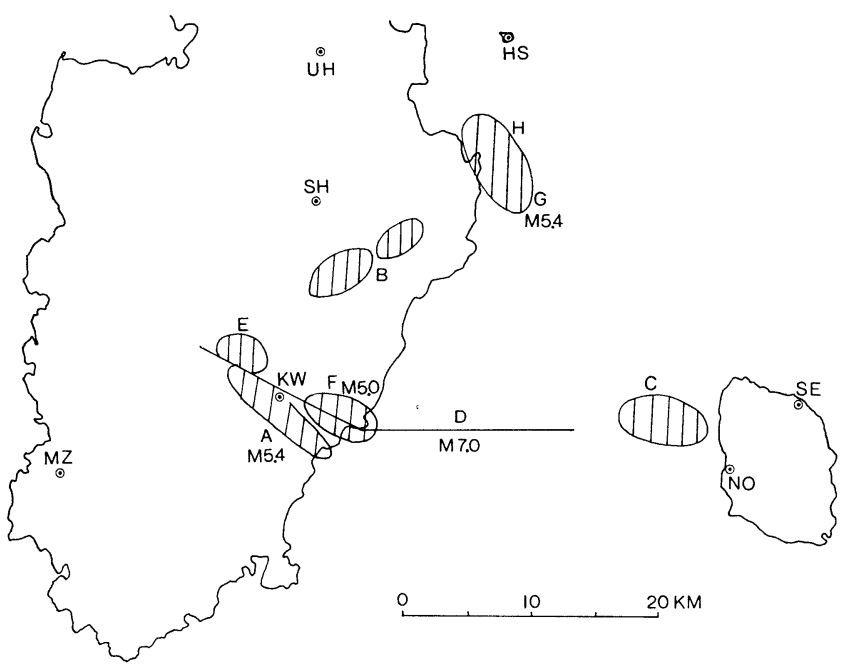

Fig. 1. Localities of stations for continuous measurements of the total intensity in the Izu Peninsula. Focal areas are indicated by hatched portions for respective earthquakes except for the $\mathrm{D}$ event which is shown by two fault lines.

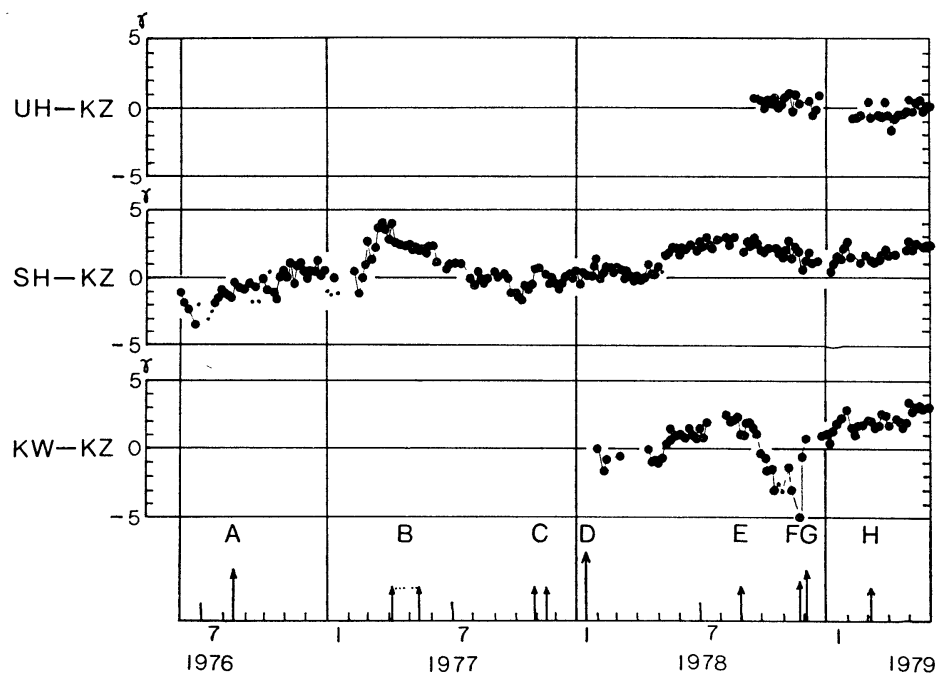

Fig. 2. Secular changes in the total intensity at the stations $\mathrm{UH}, \mathrm{SH}$, and $\mathrm{KW}$ relative to the reference station $\mathrm{KZ}$ (Kanozan Geodetic Observatory). Arrows with symbols $\mathrm{A} \sim \mathrm{H}$ indicate major earthquakes shown in Fig. 1.

and the reference station are shown in Fig. 2. The arrows with symbols $\mathrm{A} \sim \mathrm{H}$ indicate major earthquakes with their focal areas shown in Fig. 1. As clearly seen in Fig. 


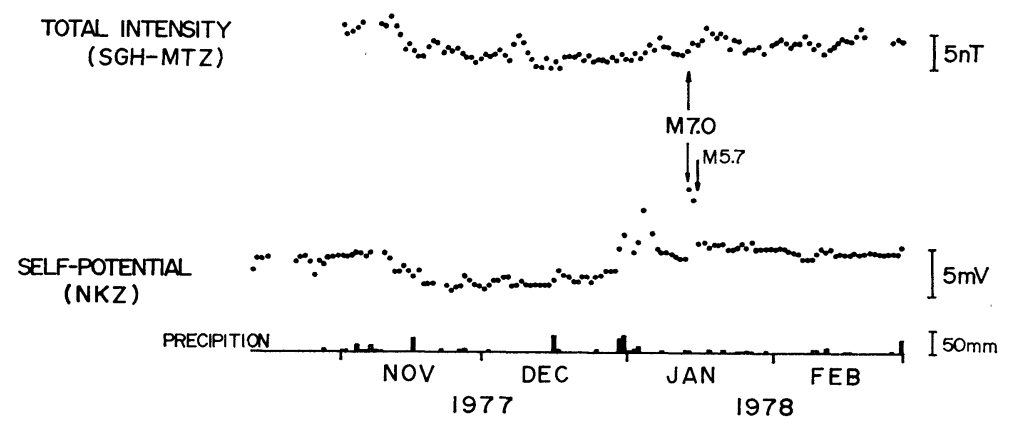

Fig. 3. Changes in total intensity difference between SGH and MTZ and in self-potential at NKZ. Arrows indicate the Izu-Oshima Kinkai earthquake of magnitude 7.0 and its largest aftershock.

2, a remarkable change was observed at $\mathrm{KW}$ presumably in association with the $\mathrm{F}$ event which took place within a distance of several kilometers from the station. Its magnitude was estimated as 5.0. About two months before this event, the total intensity began to decrease, and the trend of decrease lasted until the earthquake occurrence. The total intensity appears to have returned to the previous level immediately after the earthquake occurrence; a coseismic change amounted to $5 \mathrm{nT}$ or thereabouts.

Another striking change in the total intensity was observed in the difference between $\mathrm{SH}$ and MZ. As shown in Fig. 3, the difference (SGH-MTZ in this figure) tended to decrease about two months prior to the $\mathrm{D}$ event (indicated by two fault lines in Fig. 1), i.e. the Izu-Oshima Kinkai earthquake of magnitude 7.0, and then exhibited a tendency of gradual recovery until its occurrence. In this case, however, no marked change was observed at the time of earthquake occurrence. It seems interesting to note that the electric self-potential at the Nakaizu (NKZ) station also underwent a precursory change which is very similar in time-dependent behavior to the change in the total intensity difference. The NKZ station is very close to the SGH station and, therefore, it will be reasonably inferred that a similar change in selfpotential would have appeared at $\mathrm{SGH}$ as well.

In addition to such stations for continuous measurements, two sites (MH and YS in Fig. 5) have been established for semi-continuous measurements; that is, the total intensity is supposed to be measured at these sites whenever seismic activity becomes high in their vicinities. One of the examples of such a temporary observation is shown in Fig. 4. A proton precession magnetometer was installed at the site YSD (or YS in Fig. 5) on December 1, 1978, because unusual seismicity was found in an area several kilometers east of the site. Then an earthquake of magnitude 5.4 took place on December 3 in the area of high seismicity. The epicentral distance amounted to $5 \mathrm{~km}$ or so as shown in Fig. 9. 


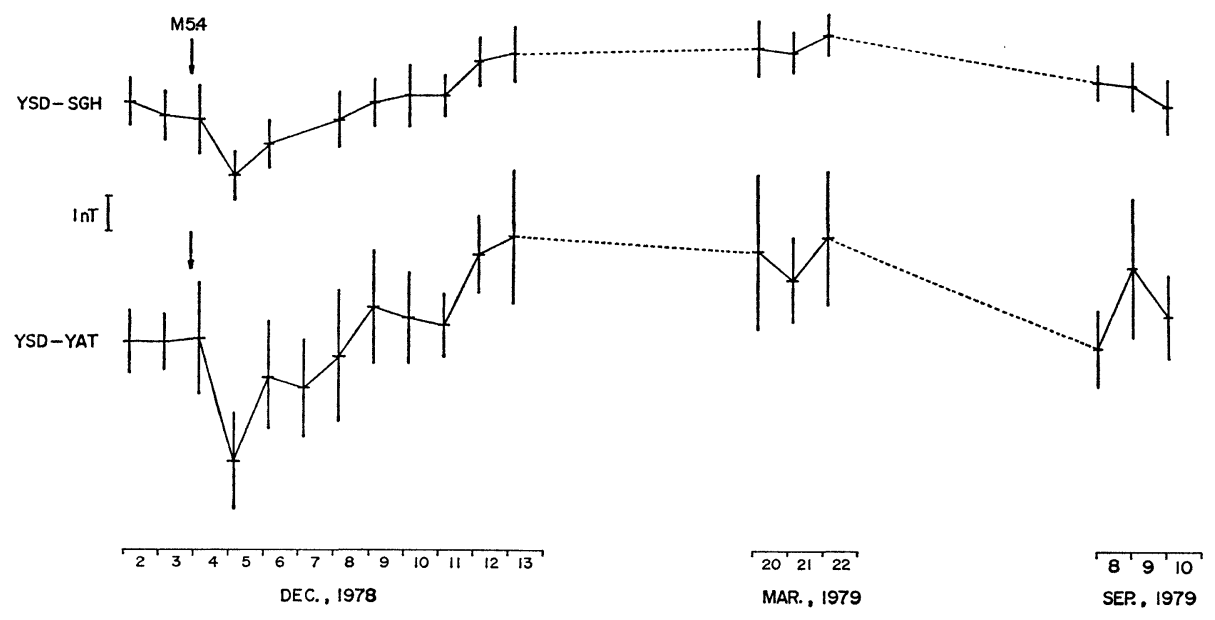

Fig. 4. Differences in the total intensity between YSD and SGH and also between YSD and YAT (Yatsugatake Magnetic Observatory). An arrow indicates the occurrence of the $M 5.4$ earthquake.

Unfortunately, the site is very close to the electric railroad as shown in Fig. 9 and the data are highly contaminated by noises. Thus, it was not clearly determined whether an abrupt change appeared at the time of earthquake occurrence. During a period from midnight to early morning the railroad is not operated and the data of good quality could be obtained. The results shown in Fig. 4 was obtained from data uncontaminated by the noises. Judging from the difference between YSD and SGH or between YSD and YAT (another remote reference station) for December 3 and 4, it does not seem likely that a coseismic change exceeding $1 \mathrm{nT}$ appeared at this site. During a few days after the earthquake, the total intensity at YSD was slightly below the level before the earthquake. It is not entirely clear whether such a decrease has something to do with the earthquake.

\section{Repeated Surveys of the Total Intensity}

The array of ERI survey sites, 22 in total, covers the eastern half of Izu Peninsula, while the Tokyo Institute of Technology (Tokyo Tech) group established 23 sites in the eastern half. Localities of the ERI and Tokyo Tech sites are shown in Fig. 5 together with stations for continuous and semi-continuous measurements of the total intensity. At each survey site a portable proton precession magnetometer is installed for 15 30 min, sometimes longer than one hour, and the total intensity is measured. every minute. The data thus obtained are compared to the corresponding ones at the nearest station for continuous measurements in the Izu Peninsula. The difference 


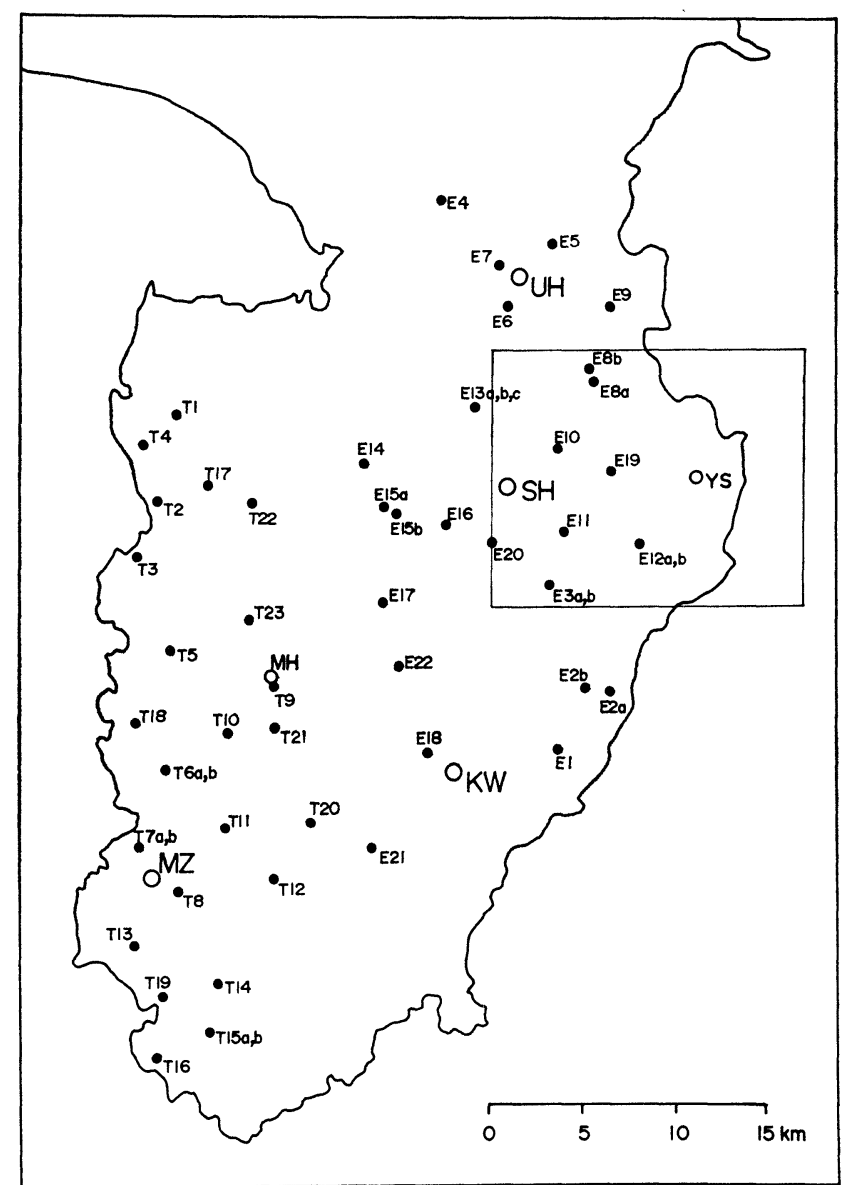

Fig. 5. Localities of sites for repeated surveys of the total intensity in the Izu Peninsula. ERI and Tokyo Tech sites are denoted by $\mathrm{E}$ and $\mathrm{T}$, respectively. Large open circles indicate continuous stations, while small ones represent sites for semi-continuous measurements of the total intensity (see text). Details in a rectangular area are shown in Fig. 9.

between such a continuous station and the remote reference stations, the Kanozan Geodetic Observatory or the Kakioka Magnetic Observatory, is determined from night-time data during each survey and, if necessary, immediately before and after the survey. Thus, the difference in the total intensity between each survey site and the reference station has been obtained.

Figures 6 and 7 show secular changes of the total intensity at each survey site relative to the reference station, the Kanozan Observatory, for the eastern and western arrays, respectively. From these figures spatial distributions of secular changes in 

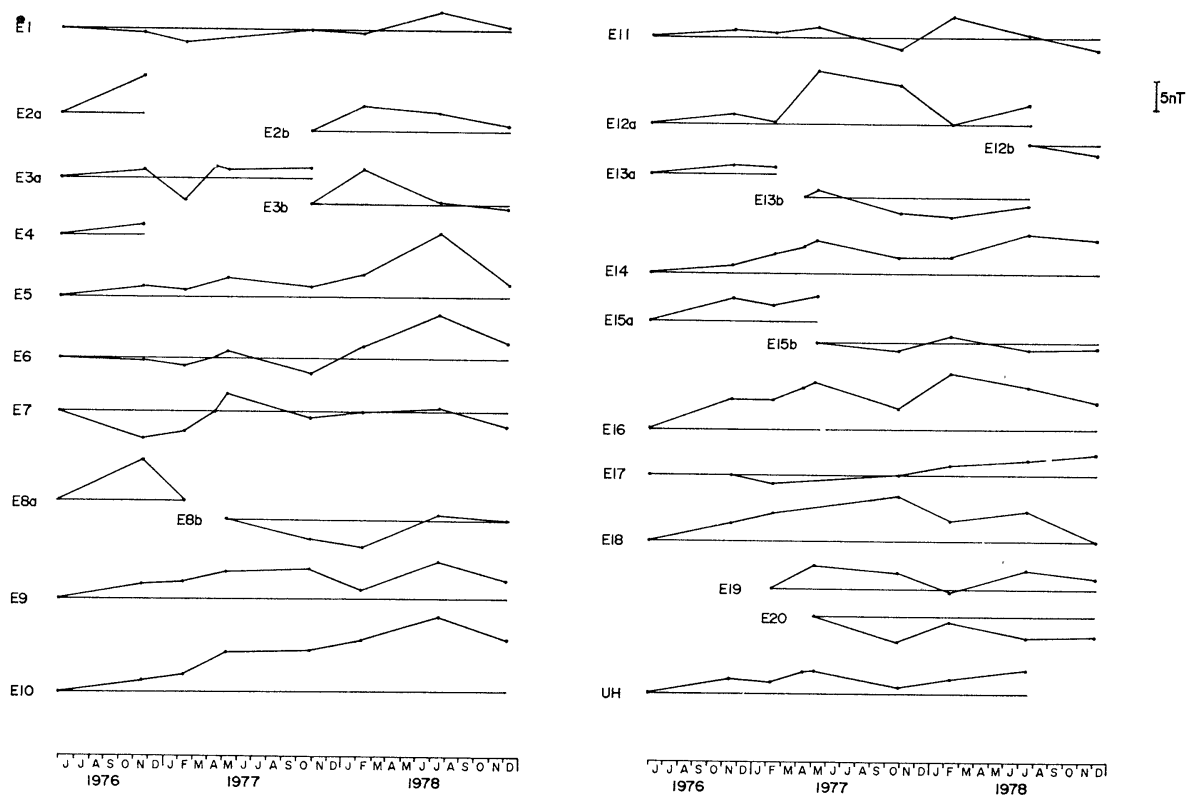

Fig. 6. Secular changes in the total intensity at ERI sites relative to the Kanozan Geodetic Observatory. A bar indicates the scale length for $5 \mathrm{nT}$.

the Izu Peninsula during a certain period can be obtained and some tectonic interpretations were given to some of the results (SASAI and IsHIKAWA, 1977, 1978; OHSHIMAN, 1980b). In this section, spatial distributions of secular changes at all the survey sites will be examined with special reference to the occurrence of the 1978 Izu-Oshima Kinkai earthquake of magnitude 7.0 (the D event denoted by fault lines in Fig. 1).

Assuming that a secular change at a site during two successive surveys can be approximated by a linear change with time, we determined secular changes during the sixmonth periods from July, 1977 to January, 1978 and from January, 1978 to July, 1978. Figure 8 shows spatial distributions of secular changes thus determined for the periods. The data of January, 1978, were obtained soon after the earthquake occurrence and, therefore, the result for the former period will include coseismic changes as well as short-term precursory changes, if any. The result for the latter period will reflect a recovery process during six months after the earthquake occurrence.

A remarkable feature can be recognized; the pattern of distributions of increase and decrease for the former period is almost exactly opposite to that for the latter period. The data at individual sites would not be unlikely to be contaminated, more or less, by some kinds of noises, particularly by the noises due to electric currents leaking from the railroads. Therefore, the amount of change might be insignificant 

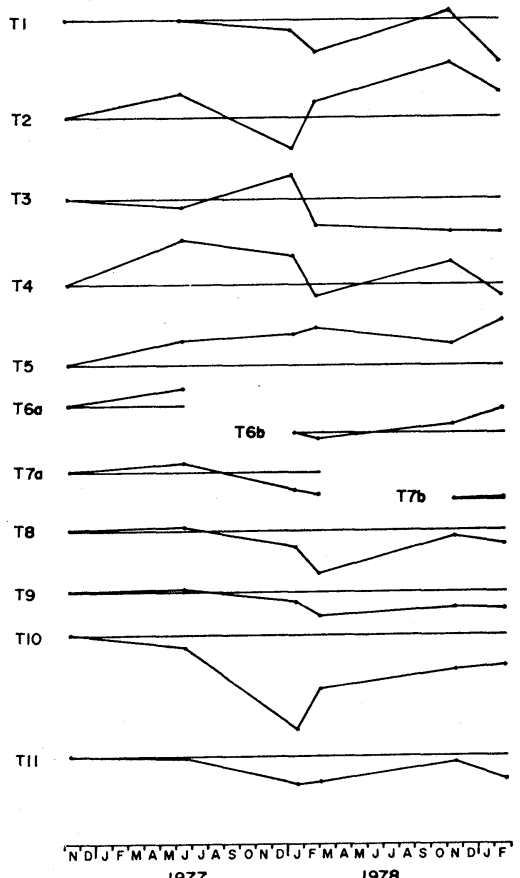
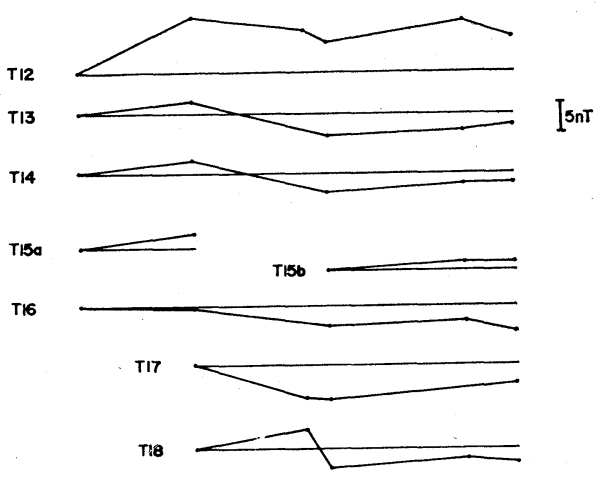

T19

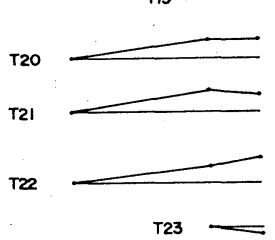

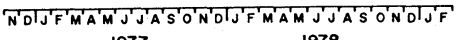
1977

Fig. 7. Secular changes in the total intensity at Tokyo Tech sites relative to the Kanozan Observatory. A bar indicates the scale length for $5 \mathrm{nT}$.

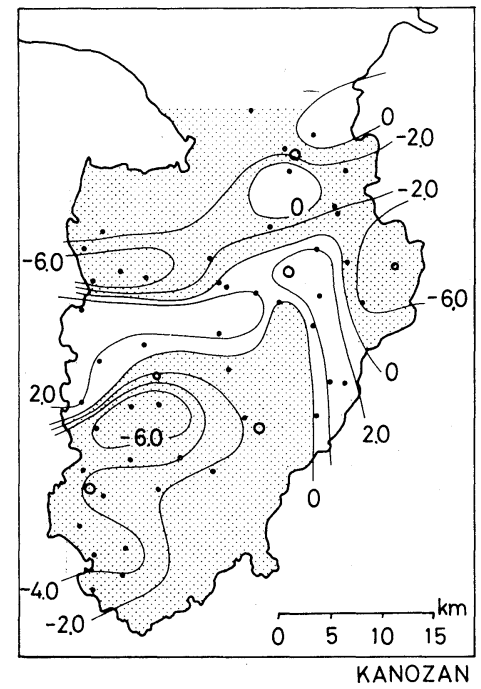

(a)

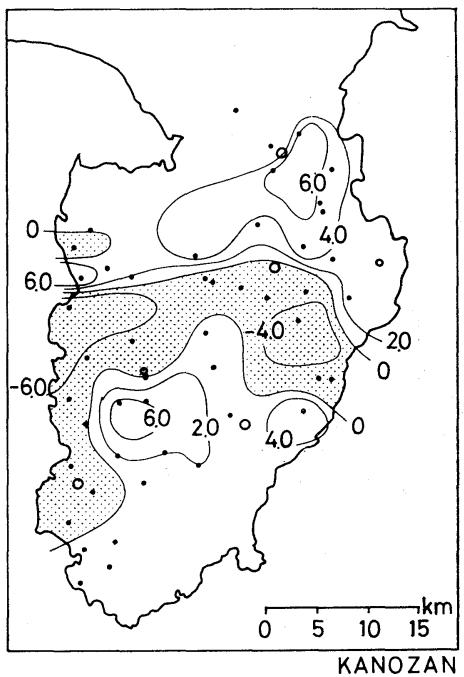

(b)

Fig. 8. Spatial distributions of secular changes in the Izu Peninsula relative to the Kanozan Observatory during periods (a) from July, 1977 to January, 1978 and (b) from January, 1978 to July, 1978. The unit for contours is given in nanoteslas. 
at some sites. However, the overall patterns shown in Fig. 8 are likely to be significant and reflect distributions of changes presumably associated with the earthquake.

\section{Repeated Surveys of Small Scale}

A station-pair difference method is more appropriate than the method described in the previous section for detecting an anomalous secular change of local nature and small magnitude (e.g. SMith and Johnston, 1976). A cooperative field work based on this survey method has been undertaken in the central area of the crustal uplift. Localities of survey sites, S1 S14, are shown in Fig. 9. The distance between two adjacent sites is shorter than $2 \mathrm{~km}$, Four sites denoted by S2, S5, S10, and S13 are also used for the repeated surveys described in the previous section. The station SGH for continuous measurements of the total intensity is also used as the reference station for this array of sites.

The present survey sites except for the four sites mentioned above were established just a few days before the occurrence of an earthquake of M5.4. All the sites were

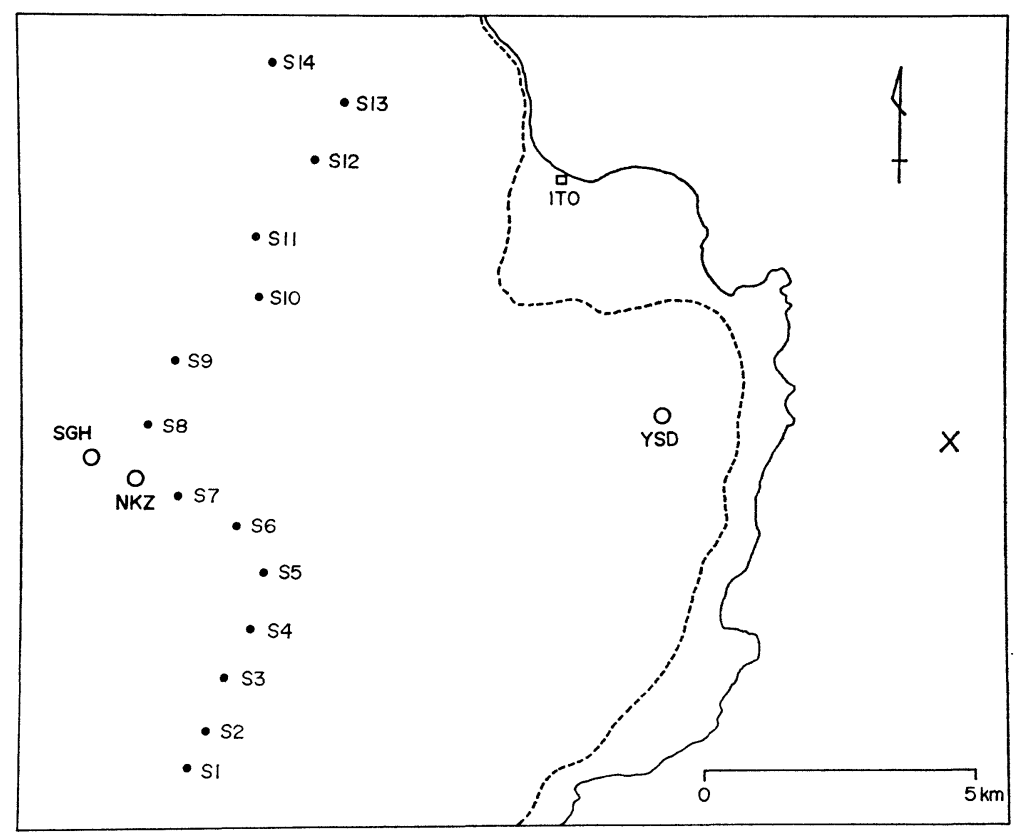

Fig. 9. Localities of sites for repeated surveys of small scale. Large open circles indicate stations for continuous (SGH) and semi-continuous (YSD) measurements of the total intensity and for measurements of short-period geomagnetic variations (NKZ). A cross represents the epicenter of the $M 5.4$ earthquake. A dashed line indicates the electric railroad. 


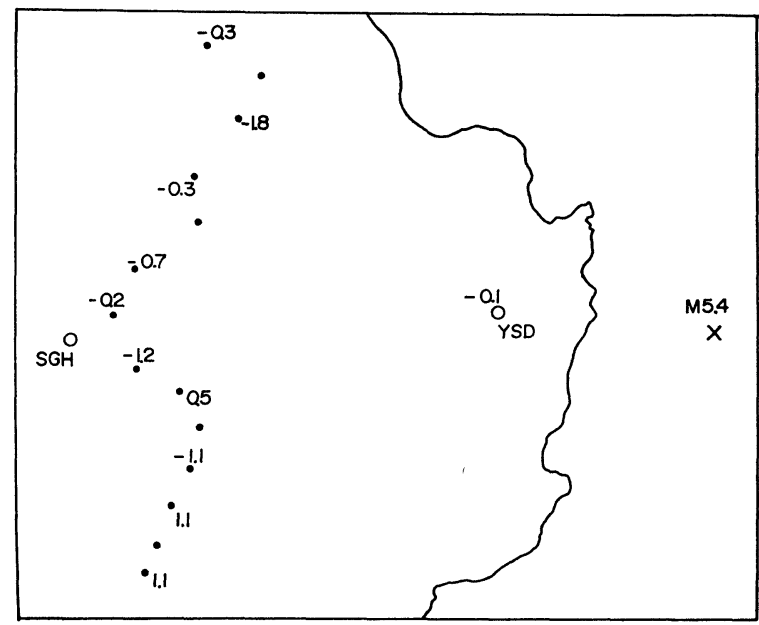

Fig. 10. Differences between the data obtained at respective sites soon after and a few days before the M5.4 event. The SGH station is taken as the reference station. The result for YSD was obtained from continuous data.

within a distance of $15 \mathrm{~km}$ from its epicenter as shown in Fig. 9. It was fortunate that the total intensity was measured for $10 \mathrm{~min}$ or so when these new sites were established. The first survey was carried out within a few days after the earthquake occurrence. It is possible, therefore, to examine whether or not any coseismic changes appeared at the survey sites, although the station-pair method is not applied in this case. Figure 10 shows changes in total intensity differences between each site and the station SGH. The result obtained at YSD was already described in Section 2. As will be mentioned below, the changes shown in Fig. 10 fall within the accuracy of the survey system. It is concluded, therefore, that no significant changes were detected, as far as total intensity differences between survey sites and SGH are concerned.

The second survey in this area was conducted in February, 1979: i.e. about two months later. Figure 11 shows changes in the total intensity at each site relative to SGH during two months after the earthquake occurrence. Compared to the result shown in Fig. 10, the changes seem to be somewhat larger. However, it will not be claimed reasonably that some of the observed changes are significant, because the survey sites are located close to the electric railroad as shown in Fig. 9 and considerable noises are expected to contaminate the observed data.

Such noises also seem to affect station-pair differences. Figure 12 shows the results obtained from the first to fifth surveys. In spite of a station separation of less than $2 \mathrm{~km}$, the differences fluctuate up to $2 \mathrm{nT}$ or so. Since survey sites were carefully selected in locations where magnetic gradients are so small that the relocation of sites can easily be made with an accuracy of less than $1 \mathrm{nT}$. Therefore, such a large 


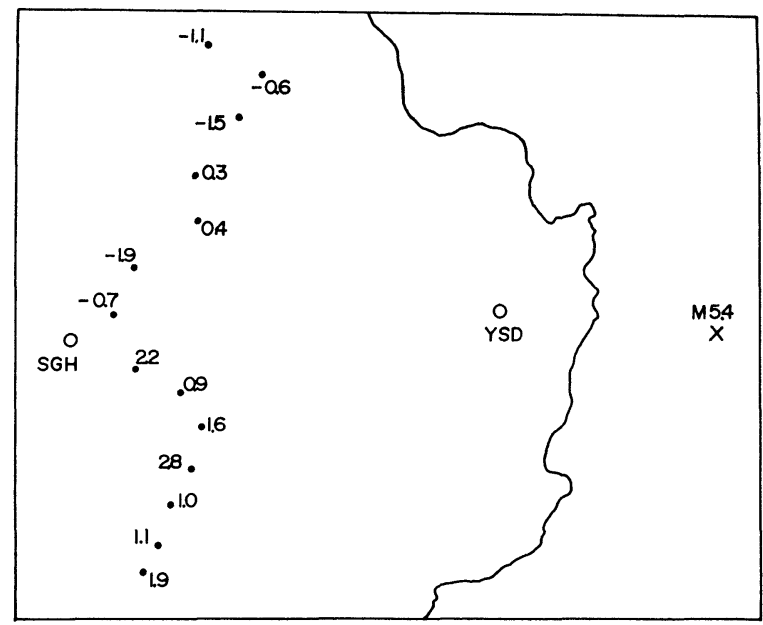

Fig. 11. Secular changes in the total intensity at each site relative to SGH during about two months after the $M 5.4$ event.

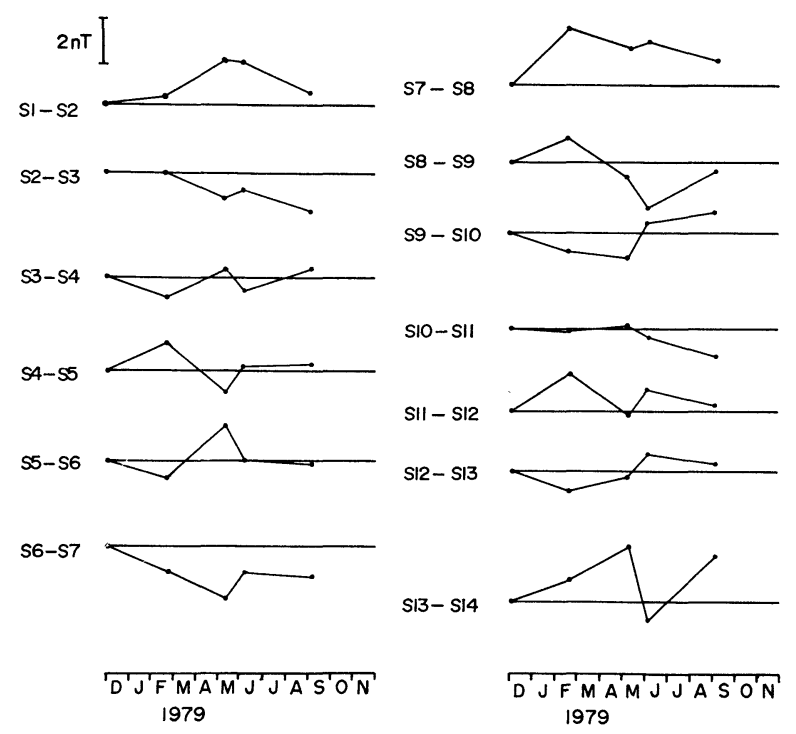

Fig. 12. Secular changes in station-pair differences of the total intensity. A bar indicates the scale length for $2 \mathrm{nT}$.

fluctuation is not likely to be due to an inaccurate relocation but rather due to noises mentioned above. A change exceeding the level of $2 \mathrm{nT}$ will be considered to be anomalous. With this error level in mind, repeated surveys will be continued and their results will be compared to time-dependent feature of crustal uplift. 
5. Observations of the Three Components of Short-Period Geomagnetic Variations

The electrical resistivity in the crust has been considered to undergo a change in association with an earthquake occurrence as clearly demonstrated by BARSUKOV (1972), MaZzella and Morrison (1974), and Yü-Lin and Fu-Ye (1978). Such a change in resistivity is also predicted in relation to dilatancy (BRACE and ORANGE, 1968; Scholz et al., 1973). Recently some attempts have been made to detect a resistivity change associated with tectonic activity by making use of electromagnetic induction methods (NiBleTt and HonkURA, 1980).

In the present case, observations of short-period geomagnetic variations have been undertaken for investigating a change in crustal resistivity. In July, 1976, a flux-gate magnetometer was installed at a station shown by NKZ in Fig. 10 and since then the three components of short-period geomagnetic variations have been measured continuously (HoNKURA and Koyama, 1978). It is well known that the amplitude of the horizontal component of short-period variations tends to be affected by local resistivity anomaly. It is expected, therefore, that the amplitude of the horizontal component will provide useful information about an underground resistivity change. In practice, a remote station is selected as the reference or control station and the ratio of the amplitude at NKZ to that at the reference station is determined. Such a procedure would be reasonable, if the scale length of external variations is much larger than the station separation.

Figure 13 shows changes in the amplitude ratio for the $H$ and $D$ components, respectively. As the reference station we selected the Yatsugatake Magnetic Observatory which is located in a seismically non-active area about $140 \mathrm{~km}$ north of NKZ. The period of variations used for the analysis is shorter than about $30 \mathrm{~min}$ in most cases. The amplitude of the $H$ component seems to have been enhanced before the earthquake of magnitude 7.0, whereas the amplitude of $D$ was depressed. A more

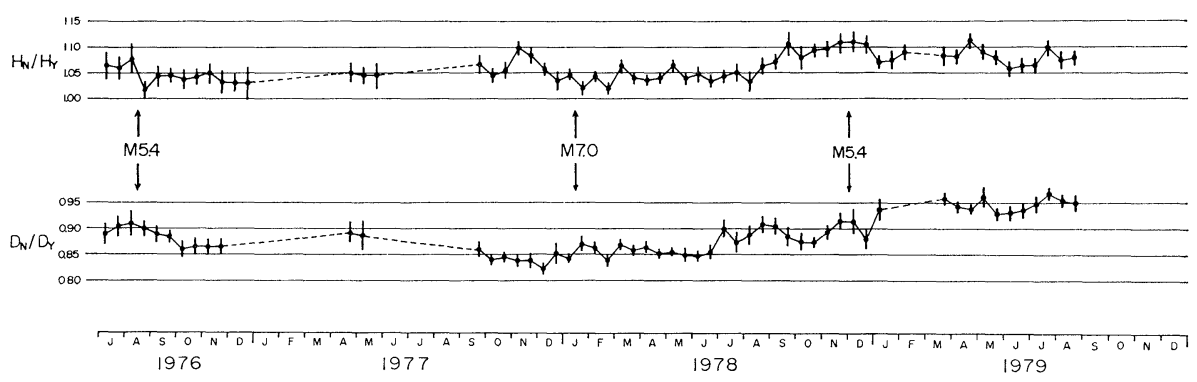

Fig. 13. Changes in $H$ and $D$ amplitudes, respectively, of short-period geomagnetic variations at NKZ relative to the Yatsugatake Magnetic Observatory. Arrows indicate occurrences of earthquakes of magnitude 5.4, 7.0, and 5.4, respectively. 
remarkable change appeared before the M5.4 earthquake of 1978. In this case, the amplitude was enhanced for both the components. However, the enhanced level has persisted even after the earthquake occurrence.

The $Z$ component was also analyzed by making use of the transfer function technique (HonkURA, 1979). As a result, it was suggested that transfer functions $\mathrm{A}$ and $\mathrm{B}$ were enhanced before the earthquake occurrence, although the changes were not very significant mainly because of large noises in transfer function estimates.

\section{Interpretations of the Changes Observed in Association with Earthquakes}

Since the beginning of the present observations of various kinds, four earthquakes of magnitude greater than 5 have taken place in the Izu Peninsula and its vicinity as shown in Fig. 1. The M5.4 event of 1976 occurred soon after the initiation of the observations and no significant result was obtained in association with this event, although slight changes in the total intensity and the resistivity were suggested from the observed data. The three other events (M7.0, M5.0, and M5.4) seem to have been accompanied by changes in the total intensity or the resistivity. In this section, an attempt will be made to interpret, rather qualitatively, the changes associated with the earthquakes.

As shown in Fig. 3, the difference in total intensity between SGH and MTZ changed about two months prior to the $M 7.0$ event. The change in self-potential at NKZ (very close to SGH) is very similar to the above change in the total intensity difference. It seems likely, therefore, that these two types of changes are of the same origin. Moreover, the time-dependent nature of the changes seems to be characterized. by a diffusion process. The above two facts suggest that the self-potential change would reflect a streaming potential created as a result of underground water flow (Mizutani et al., 1976; CorWIN and Morrison, 1977) and the change in the magnetic field would have resulted from the electrokinetic effect (MIZUTANI and IsHIDO, 1976).

Such an interpretation appears to be supported further by a resistivity change as implied by changes in the amplitude of short-period variations. HonKURA (1978) pointed out a good coincidence in appearance of the above three kinds of changes and presumed that underground water might have begun to flow into the focal area about two months prior to the earthquake. Honkura (1979) also showed that the changes in transfer functions could be interpreted reasonably by the above process, although the interpretation is based on a rather qualitative argument.

An interpretation which is completely different from the above one based on the electrokinetic effect can also be considered for the change in the total intensity: the piezomagnetic effect. There exists an evidence supporting such a piezomagnetic origin. As can be recognized in Fig. 14, striking changes in the total intensity at MTZ appears to be correlated with rather abrupt changes in strain at Irozaki situated at the southern-most tip of Izu Peninsula. However, it remains unclear why no re- 


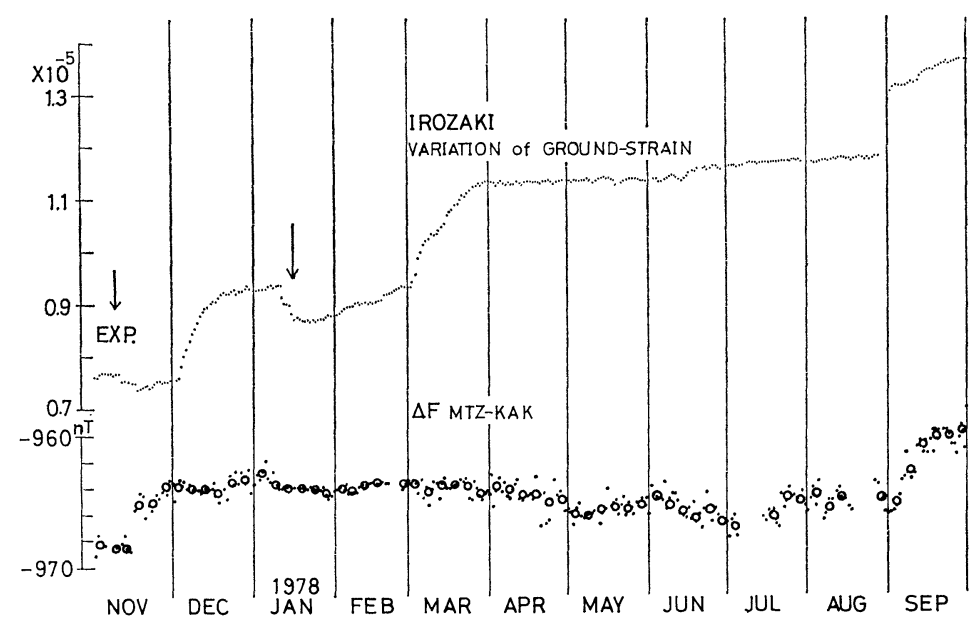

Fig. 14. Variations in strain at Irozaki and secular changes in total intensity difference between MTZ and KAK (Kakioka Magnetic Observatory). An arrow shown in the time interval for January represents the occurrence of the Izu-Oshima Kinkai earthquake of magnitude 7.0.

markable change appeared in the total intensity at the time of earthquake occurrence as denoted by an arrow in Fig. 14. Also the change in strain observed in March is not accompanied by a change in the total intensity. One of the possibilities would be that the stress distribution was such a one as causes no change in the total intensity at MTZ.

The changes in the total intensity shown in Fig. 8 (a) can be considered to be mostly coseismic changes. An attempt was made to interpret the coseismic changes in terms of fault displacement associated with the $M 7.0$ event. Figure 15 shows the result obtained from numerical calculations for displacements of three faults (OHSHIMAN, 1980a). It is clearly recognized from Figs. 8(a) and 15 that the calculated result accounts for the overall pattern of coseismic changes fairly well except for the northwestern area.

On the other hand, Fig. 8(b) seems to reflect changes during a six-month period after the earthquake. That the pattern during the post-earthquake period is quite opposite to that of coseismic changes suggests a recovery process in and around the focal area after the earthquake occurrence. Such a process may have something to do with a possible redistribution of residual stress.

The change in the total intensity observed prior to the $M 5.0$ event is one of the most representative precursory changes. Since a coseismic change was also observed. very clearly, such changes are likely to be of piezomagnetic origin. If this is the case, the stress state must have changed rather rapidly before the earthquake occurrence; 


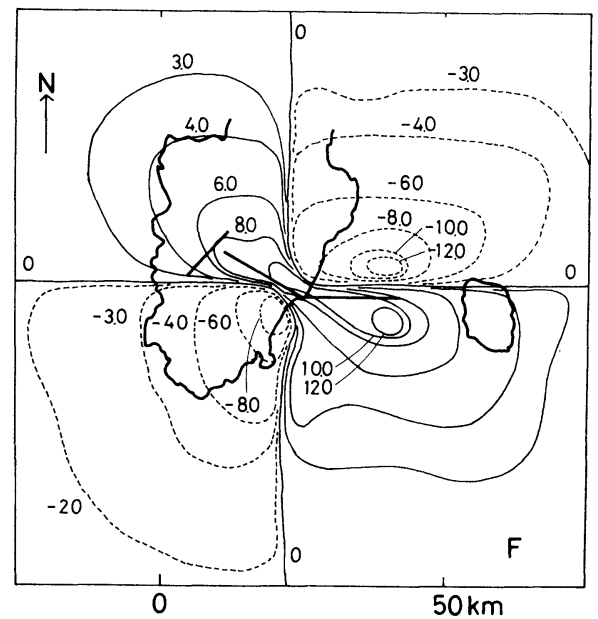

Fig. 15. Coseismic changes to be expected from seismomagnetic calculations for displacements of a main fault and two sub-faults as shown by straight lines. The unit for contours is given in nanoteslas. Details are described in OHSHIMAN (1980a).

presumably during about two months. Such a change might be due to a stress redistribution before the shock occurring in and around the focal area as a result of a preseismic fault-slip or other processes.

In the case of the M5.4 event of 1978, no coseismic change was observed. However, the possibility cannot be ruled out that the station happened to be located at an area where only a slight coseismic change appears as a result of fault displacement.

As for the amplitude of short-period geomagnetic variations, fairly large changes appeared some months prior to this M5.4 event. However, the changes seem to persist even over a period of several months after the event. According to the result of levelling surveys and also to sea levels obtained from tidal data, an uplift amounting to $5 \mathrm{~cm}$ or so appeared in association with this earthquake and it has not recovered yet (GeOGRAPHICAL SURVEY InSTITUTE, 1979, 1980). Whatever mechanism is responsible to such an uplift, a porosity increase will not be unlikely. If underground water flowed into pores and cracks newly created, the electrical resistivity will decrease, resulting possibly in a change in the amplitude of short-period geomagnetic variations at the NKZ station. It is inferred, therefore, that the changes observed at NKZ would reflect a resistivity change associated with the crustal uplift which seems to have something to do with the occurrence of the M5.4 earthquake.

\section{Discussion}

Magnetic and electric observations in the Izu Peninsula have provided many important results from the viewpoint of earthquake prediction studies. Some of the 
changes in the geomagnetic field were interpreted in terms of changes in rock magnetization due to stress. Coseismic changes would reasonably be interpreted by such a mechanism. It is still unknown, however, whether or not changes during pre- or post-earthquake periods, amounting to almost the same magnitude as coseismic ones, are accounted for by a similar mechanism. In other words, the question is whether or not a relatively rapid change in stress state takes place shortly before and after an earthquake occurrence.

As far as the change in the total intensity that appeared before the $M 7.0$ event is concerned, two mechanisms were considered for its interpretation; rock magnetization changes due to a change in stress state and the creation of a magnetic field due to the electrokinetic effect. There are three observed results that seem to support the latter; no coseismic change, the change very similar to the self-potential change, and the nature characterized by a diffusion process. On the other hand, the former seems to be supported by a good correlation between the changes in strain and total intensity. At present, no decisive conclusion can be drawn as to which mechanism is the case.

An attempt to investigate resistivity changes by making use of short-period geomagnetic variations seems to be somewhat successful and worth further investigation. If this method turns out to be promising, monitoring of resistivity changes will easily be made, compared to the well-known method based on artificial electric currents as used in the U.S.S.R. (BARSuKov, 1972), the U.S.A. (MAZzella and Morrison, 1974), and China (YÜ-LIN and FU-YE, 1978), although the latter method is certainly better in accuracy of measurements and also in interpretation of resistivity changes.

Finally, the authors point out the importance of simultaneous observations of various sorts such as the geomagnetic field and its variation, the electric field, the resistivity, and so on. Such a combination of observations will be helpful in the detection of anomalous phenomena associated with an earthquake occurrence and their interpretation which would possibly contribute to the understanding of an underground process closely related to an earthquake occurrence.

\section{REFERENCES}

BARSUKOV, O. M., Variations of electric resistivity of mountain rocks connected with tectonic causes, Tectonophysics, 14, 273-277, 1972.

Brace, W. F. and A. S. Orange, Electrical resistivity changes in saturated rocks during fracture and frictional sliding, J. Geophys. Res., 73, 1433-1445, 1968.

Corwin, R. F. and H. F. Morrison, Self-potential variations preceding earthquakes in central California, Geophys. Res. Lett., 4, 171-174, 1977.

Earthquake Prediction Observation Center, Summary of field observational work on the recent crustal activity in Izu Peninsula, Bull. Earthq. Res. Inst., Univ. Tokyo, 52, 111-112, 1977 (in Japanese with English abstract).

Geographical Survey Institute, Crustal deformation in the central part of Izu-Peninsula, Rep. Coord. Comm. Earthq. Predict., 16, 82-87, 1976 (in Japanese).

Geographical Survey Institute, Crustal deformation in the eastern Izu District, Rep. Coord. Comm. 
Earthq. Predict., 22, 68-71, 1979 (in Japanese).

Geographical Survey Institute, Crustal deformation in the eastern Izu District, Rep. Coord. Comm. Earthq. Predict., 23, 48-52, 1980 (in Japanese).

HoNKURA, Y., On a relation between anomalies in the geomagnetic and telluric fields observed at Nakaizu and the Izu-Oshima-Kinkai earthquake of 1978, Bull. Earthq. Res. Inst., Univ. Tokyo, 53, 931-937, 1978 (in Japanese with English abstract).

HoNkURA, Y., Observations of short-period geomagnetic variations at Nakaizu (2): changes in transfer functions associated with the Izu-Oshima-Kinkai earthquake of 1978, Bull. Earthq. Res. Inst., Univ. Tokyo, 54, 477-490, 1979.

HoNKURA, Y. and S. KoYAMA, Observations of short-period geomagnetic variations at Nakaizu (1), Bull. Earthq. Res. Inst., Univ. Tokyo, 53, 925-930, 1978 (in Japanese with English abstract).

Koyama, S. and Y. Honkura, Observation of electric self-potential at Nakaizu (1), Bull. Earthq. Res. Inst., Univ. Tokyo, 53, 939-942, 1978 (in Japanese with English abstract).

Mazzella, A. and H. F. MorRison, Electrical resistivity variations associated with earthquakes on the San Andreas fault, Science, 185, 855-857, 1974.

Mizutani, $H$. and T. Ishido, A new interpretation of magnetic field variation associated with the Matsushiro earthquakes, J. Geomag. Geoelectr., 28, 179-188, 1976.

MizUTANI, H., T. Ishido, Y. YoKoKURA, and S. OHNishI, Electrokinetic phenomena associated with earthquakes, Geophys. Res. Lett., 3, 365-368, 1976.

Niblett, E. R. and Y. HonkURA, Time-dependence of electromagnetic transfer functions and their association with tectonic activity, J. Geomag. Geoelectr., 32, 1980 (in press).

OHChi, K., N. IJichi, M. KuWASHIma, and M. KaWAmURA, Geomagnetic total force intensity variation associated with the Izu-Oshima Kinkai earthquake, 1978, Mem. Kakioka Mag. Obs., 18, 55-64, 1979 (in Japanese with English abstract).

OHshiman, N., Local geomagnetic changes associated with fault activity, M. Sc Thesis, Tokyo Inst. Tech., 178 pp., 1980 a.

OHSHIMAN, N., Underground magnetic dipole representing a seismomagnetic effect, J. Geomag. Geoelectr., 32, $1980 \mathrm{~b}$ (in press).

SASAI, Y. and Y. IshIKAWA, Changes in the geomagnetic total force intensity associated with the anomalous crustal activity in the eastern part of the Izu Peninsula (1), Bull. Earthq. Res. Inst., Univ. Tokyo, 52, 173-190, 1977 (in Japanese with English abstract).

SASAI, Y. and Y. IshIKAWA, Changes in the geomagnetic total force intensity associated with the anomalous crustal activity in the eastern part of the Izu Peninsula (2), Bull. Earthq. Res. Inst., Univ. Tokyo, 53, 893-923, 1978 (in Japanese with English abstract).

Scholz, C. H., L. R. SyKes, and Y. P. AgGARwaL, Earthquake prediction: a physical basis, Science, 181, 803-810, 1973.

ShimazaKi, K. and P. Somerville, Summary of the static and dynamic parameters of the IzuOshima-Kinkai earthquake of January 14, 1978, Bull. Earthq. Res. Inst., Univ. Tokyo, 53, 613628, 1978.

Smith, B. E. and M. J. S. Johnston, A tectonomagnetic effect observed before a magnitude 5.2 earthquake near Hollister, California, J. Geophys. Res., 81, 3556-3560, 1976.

Sumiтomo, N., Geomagnetism in relation to tectonic activities of the earth's crust in Japan, J. Phys. Earth, 25, Suppl., S147-S160, 1977.

TANAKa, $\mathrm{H}$. and N. Ohshiman, Changes in the geomagnetic total force observed in the western part of the Izu Peninsula associated with the 1978 near-Izu-Oshima Island earthquake, Rep. Coord. Comm. Earthq. Predict., 20, 77-80, 1978 (in Japanese).

Tsumura, K., I. Karakama, I. Ogino, K. SaKai, and M. TaKahashi, Observation of the earthquake swarm in the Izu Peninsula (1975-1977), Bull. Earthq. Res. Inst., Univ. Tokyo, 52, 113-140, 1977 
(in Japanese with English abstract).

Tsumura, K., I. KaraKama, I. Ogino, and M. TAKahashi, Seismic activities before and after the IzuOshima-Kinkai earthquake of 1978, Bull. Earthq. Res. Inst., Univ. Tokyo, 53, 675-706, 1978 (in Japanese with English abstract).

Yü-LIN, Z. and Q. FU-YE, Electrical resistivity anomaly observed in and around the epicentral area prior to the Tangshan earthquake of 1976, Acta Geophys. Sinica, 21, 181-190, 1978 (in Chinese with English abstract). 